Open Access

\title{
Correction to: The role of fibrinolysis inhibition in engineered vascular networks derived from endothelial cells and adipose- derived stem cells
}

Severin Mühleder ${ }^{1,2 \dagger}$, Karoline Pill ${ }^{1,2 \dagger}$, Mira Schaupper ${ }^{1,2,6 \dagger}$, Krystyna Labuda ${ }^{1,2}$, Eleni Priglinger ${ }^{1,2}$, Pablo Hofbauer $^{3}$, Verena Charwat ${ }^{4}$, Uwe Marx ${ }^{5}$, Heinz Redl ${ }^{1,2}$ and Wolfgang Holnthoner ${ }^{1,2^{*}}$

\section{Correction}

The original article [1] contains numerous value errors in the graphs in Fig. $2 \mathrm{~b}$ regarding the markers describing the values for total tubule length and mean tubule length without aprotinin at $2.5 \mathrm{mg} / \mathrm{ml}$ concentration of fibrinogen. The corrected version of this figure can be viewed ahead.

* Correspondence: wolfgang.holnthoner@trauma.lbg.ac.at

† Severin Mühleder, Karoline Pill and Mira Schaupper contributed equally to this work.

'Ludwig Boltzmann Institute for Experimental and Clinical Traumatology, AUVA Research Centre, Donaueschingenstrasse 13, A-1200 Vienna, Austria

${ }^{2}$ Austrian Cluster for Tissue Regeneration, Vienna, Austria

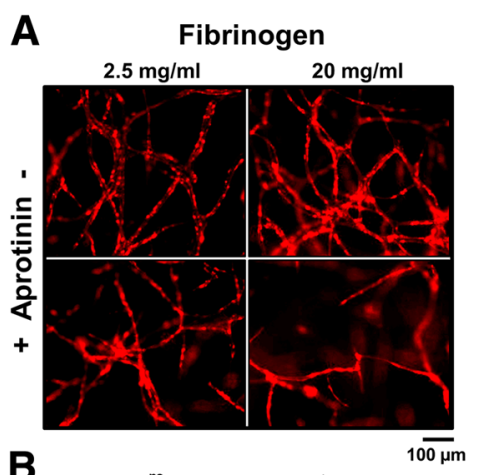

B
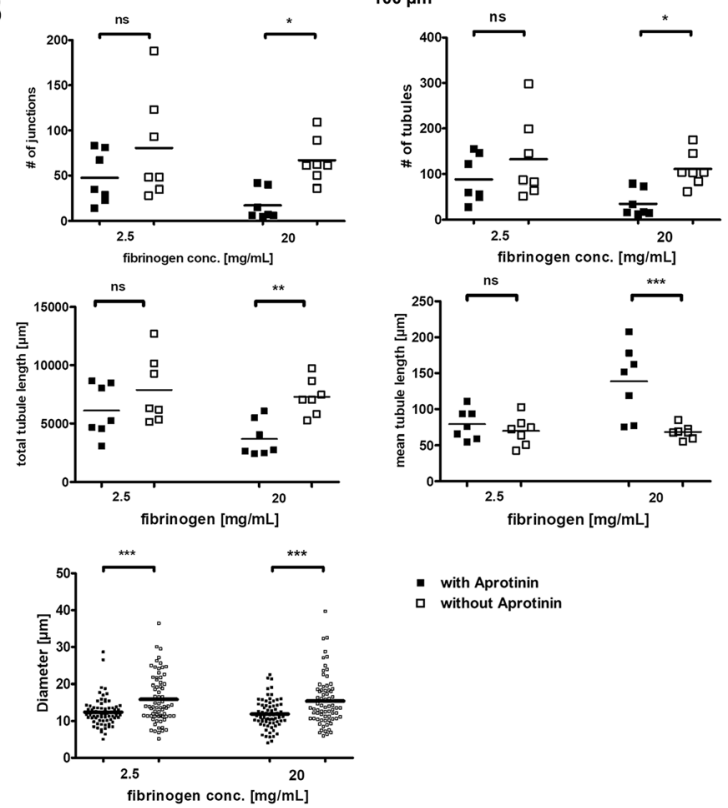

- with Aprotinin without Aprotinin 


\section{Author details}

${ }^{1}$ Ludwig Boltzmann Institute for Experimental and Clinical Traumatology, AUVA Research Centre, Donaueschingenstrasse 13, A-1200 Vienna, Austria. ${ }^{2}$ Austrian Cluster for Tissue Regeneration, Vienna, Austria. ${ }^{3}$ Institute of Molecular Biotechnology of the Austrian Academy of Science (IMBA), Vienna Biocenter (VBC), Vienna, Austria. ${ }^{4}$ Department of Biotechnology, University of Natural Resources and Life Sciences (BOKU), Vienna, Austria. ${ }^{5}$ TissUse GmbH, Berlin, Germany. ${ }^{6}$ Present address: Division of Plastic and Reconstructive Surgery, Department of Surgery, Medical University of Vienna, Vienna, Austria.

Received: 27 June 2018 Revised: 29 August 2018

Accepted: 29 August 2018 Published online: 07 October 2018

\section{Reference}

1. Mühleder $\mathrm{S}$, et al. The role of fibrinolysis inhibition in engineered vascular networks derived from endothelial cells and adipose-derived stem cells. Stem Cell Res Ther. 2018;9:35. https://doi.org/10.1186/s13287-017-0764-2 